\title{
Delays in the treatment of cauda equina syndrome due to its variable clinical features in patients presenting to the emergency department
}

\author{
Ibrahim Jalloh, Pawan Minhas
}

Emerg Med J 2007;24:33-34. doi: 10.1136/emj.2006.038182

Objective: To identify reasons for delay in management of patients with cauda equina syndrome (CES) and to determine commonly presented features of CES.

Methods: Retrospectively, the presenting features and management of patients treated for CES over a 4 -year period were reviewed.

Results: Reasons for delay in treatment were identified in over half of the patients.

Discussion: Most patients do not present with all the characteristic features of CES. Sacral sensory loss is a sensitive and relatively specific sign for diagnosing CES.

$\mathrm{P}$ atients with cauda equina syndrome (CES) characteristically present with a history of lower back pain, bilateral sciatica, motor and sensory disturbance including sacral and perianal anaesthesia, and sphincter disturbance. It may progress to permanent sensory loss, motor loss and incontinence. ${ }^{1-3}$ Emergent decompression of CES is important in improving the outcome. A meta-analysis involving 322 patients from 104 studies showed that considerable improvements in sensory, motor and sphincter deficits were possible if surgery was performed within $48 \mathrm{~h}^{4}$

Many patients presenting with CES do not receive an urgent referral to a specialist. Difficulties in diagnosis may arise because of the variability of the clinical features that are present on attendance to the emergency department, and also because of the association of urinary retention and constipation with pain and opioid analgesia.

The purpose of this study was to identify reasons for delay in management and to see which features of this syndrome patients present with.

\section{METHODS}

Retrospectively, the case notes of patients transferred to St George's Hospital, London neurosurgical centre between 2001 and 2005 with a confirmed diagnosis of CES on magnetic resonance imaging were reviewed.

\section{RESULTS}

In all, 32 patients with CES (53\% men; mean age 46.8 years, range $20-80$ years) presented to nine different emergency departments. Table 1 shows the proportion of patients presenting with particular symptoms and signs.

In all, $6(19 \%)$ patients presented with the symptom cluster of lower back pain, bilateral sciatica, motor loss, sacral sensory loss and sphincter disturbance.

On those patients operated on $(n=29)$, the mean length of time from presentation to operation was $31.3 \mathrm{~h}$ (range 6-76 h) and $90 \%$ of patients were operated on within $48 \mathrm{~h}$. Three patients were not operated on, two of whom were deemed to have been referred too late for surgical intervention to be worthwhile and one patient who developed unrelated medical problems.

Figure 1 shows that there is some correlation between the time from presentation to operation and the number of clinical features of CES documented on presentation.

\section{REASONS FOR DELAY}

Table 2 lists the clearly identifiable reasons for surgical treatment delay in about half of the patients.

\section{DISCUSSION}

Delays in the treatment of CES were most often due to delay in making the diagnosis. Predictably, this was more likely when fewer features of CES were established at the time of presentation.

Only $19 \%$ of patients presented with the characteristic combination of bilateral sciatica, lower limb weakness, saddle anaesthesia and sphincter disturbance. Table 1 shows that the strongest presenting features of CES are lower back pain, sacral sensory loss and urinary symptoms.

\section{CONCLUSION}

Patients may not clearly manifest all the characteristic features of CES. Diagnosis is also complicated by sphincter disturbance due to pain and opioid-based analgesia. By highlighting the importance of examining for sacral sensory loss as a sensitive and relatively specific sign that is quick and easy to examine for, clinicians will be quicker in recognising it and thus improve outcomes in patients with CES.

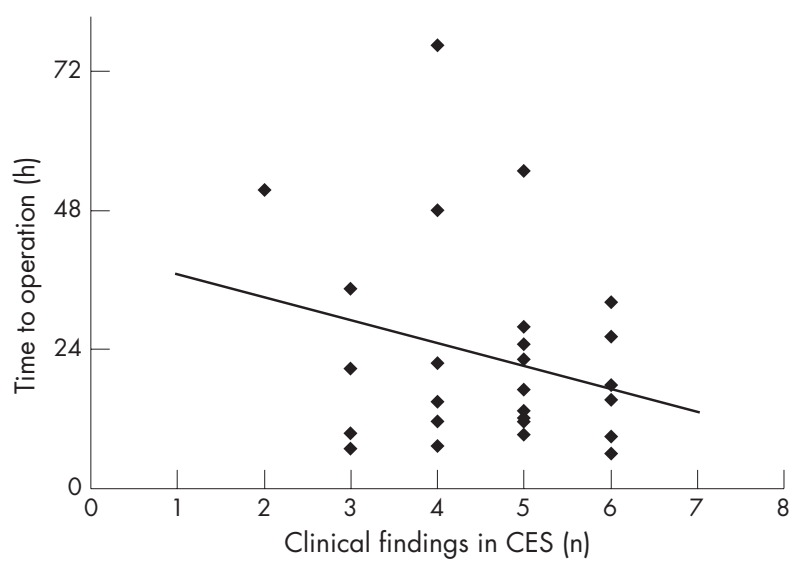

Figure 1 Number of clinical findings in patients with cauda equina syndrome (CES) versus time to operation. Clinical findings defined as lower back pain, sciatica, motor loss, sensory loss, reflex loss and sphincter disturbance.

Abbreviation: CES, cauda equina syndrome 
Table 1 Clinical features of patients presenting with cauda equina syndrome $(n=32)$

\begin{tabular}{|c|c|c|c|c|c|c|c|c|c|c|}
\hline \multirow[b]{2}{*}{$\begin{array}{l}\text { Lower } \\
\text { back pain } \\
n=32\end{array}$} & \multirow[b]{2}{*}{$\begin{array}{l}\text { Sciatica } \\
n=25\end{array}$} & \multicolumn{3}{|c|}{ Sensory loss } & \multirow[b]{2}{*}{$\begin{array}{l}\text { Motor loss } \\
n=31\end{array}$} & \multicolumn{2}{|c|}{ Motor reflex loss } & \multicolumn{3}{|l|}{ Sphincters } \\
\hline & & $\begin{array}{l}\text { Legs } \\
n=30\end{array}$ & $\begin{array}{l}\text { Sacral } \\
n=27\end{array}$ & $\begin{array}{l}\text { Perianal } \\
n=24\end{array}$ & & $\begin{array}{l}\text { Knee } \\
n=22\end{array}$ & $\begin{array}{l}\text { Ankle } \\
n=22\end{array}$ & $\begin{array}{l}\text { Urinary } \\
\text { symptoms } \\
n=31\end{array}$ & $\begin{array}{l}\text { Rectal } \\
\text { symptoms } \\
n=31\end{array}$ & $\begin{array}{l}\text { Decreased } \\
\text { anal tone } \\
n=23\end{array}$ \\
\hline 94 & $\begin{array}{l}44 \text { (bi) } \\
48 \text { (uni) }\end{array}$ & $\begin{array}{l}30 \text { (bi) } \\
37 \text { (uni) }\end{array}$ & 85 & 75 & $\begin{array}{l}32 \text { (bi) } \\
32 \text { (uni) }\end{array}$ & $\begin{array}{l}9 \text { (bi) } \\
14 \text { (uni) }\end{array}$ & $\begin{array}{l}46 \text { (bi) } \\
18 \text { (uni) }\end{array}$ & 84 & 35 & 78 \\
\hline
\end{tabular}

bi, bilateral symptoms or signs; uni, unilateral symptoms or signs.

All values are percentages.

Table 2 Reasons identified for delay in management of cauda equina syndrome

\begin{tabular}{ll}
\hline Patient-related factors & 1 \\
Presented too late & 2 \\
Complicating medical comorbidity & 4 \\
Physician-related factors & 2 \\
CES not considered & 2 \\
$\quad$ Referral to inappropriate specialty & 2 \\
Inappropriate initial management & \\
$\quad$ Inappropriate advice from neurosurgical or & \\
orthopaedic team & \\
Other factors & 2 \\
$\quad$ No beds in the tertiary centre & 1 \\
$\quad$ Mechanical failure of MRI scanner & \\
\hline CES, cauda equina syndrome; MRI, magnetic resonance \\
imaging.
\end{tabular}

\section{Authors' affiliations}

Ibrahim Jalloh, St Mary's Hospital, London, UK

Pawan Minhas, St George's Hospital, London, UK

Competing interests: None.

Correspondence to: Mr Ibrahim Jalloh, 143 Albion Road, London N16 9JU, UK; ibjalloh@gmail.com

Accepted January 2006

\section{REFERENCES}

1 Jennett WB. A study of 25 cases of compression of the cauda equina by prolapsed intervertebral discs. J Neurol Neurosurg Psychiatry 1956;19:109-16. 2 Malloch JD. Acute retention due to intervertebral disc prolapse. Br J Urol 1965;37:578.

3 Shapiro S. Cauda equina syndrome secondary to lumbar disc herniation. Neurosurgery 1993;32:743-7.

4 Ahn UM, Ahn NU, Buchowski JM, et al. Cauda equina syndrome secondary to lumbar disc herniation. A meta-analysis of surgical outcomes. Spine 2000;25:1515-22. 